\title{
A PERGUNTA SOB UM NOVO OLHAR NO PROCESSO EDUCATIVO- RELIGIOSO ${ }^{1}$
}

\author{
QUESTION UNDER A NEW LOOK \\ IN RELIGIOUS EDUCATION PROCESS
}

REMÍ KLEIN ${ }^{(*)}$

\begin{abstract}
RESUMO
$\mathrm{Na}$ educação atual a pergunta está muito associada ao papel do professor e à função da avaliação, cabendo ao aluno dar a resposta certa. Assim, longe de ser uma pedagogia da pergunta, a prática educativa em geral tornou-se uma pedagogia da resposta. Diante desta percepção epistemológica, pedagógica e metodológica, o artigo propõe uma reflexão sobre o lugar e o papel da pergunta no processo educativo e, de modo especial, no processo educativoreligioso, sob o argumento de que uma construção social e existencial do conhecimento se dá a partir da pergunta e da curiosidade do ser humano. Por meio de um estudo bibliográfico, a partir de referenciais da maiêutica de Sócrates, da pedagogia de Jesus, dos catecismos de Lutero, da filosofia para crianças de Lipman, da proposta pedagógica de Freire e dos Parâmetros Curriculares Nacionais de Ensino Religioso do FONAPER, dentre outros, busca-se fundamentar uma pedagogia da pergunta a ser repensada, redescoberta e ressignificada na práxis educativoreligiosa em famílias, escolas, comunidades eclesiais e outros contextos educacionais.
\end{abstract}

PalaVRas-ChaVe: Processo educativo-religioso. Pedagogia. Pergunta. Conhecimento.

\begin{abstract}
The question under a new perspective in the religious-educative process. In the current education the question is much associated with the role of the teacher and the evaluation function, being up to the student to give the correct answer. Thus, far from being a question pedagogy, educational practice in general has become a answer pedagogy. Faced with this epistemological, pedagogic and methodological perception, the article proposes a refletion about the place and the role of the question in the educative process and, in a special way, in the religious-educative process, under the argument that a social and existential construction of knowledge takes place motivated by the question and curiosity of the human being. Through a bibliographic study based on referentials from Socrates' maiuetic, Jesus' pedagogy, Luther's cathecisms, Lipman's philosophy for children, Freire's pedagogical proposal and the National Curricular Parameters for Religious Education of FONAPER, among others, one seeks to based foundations for a pedagogy of the question to be rethought, rediscovered and resignified in the religious-educative practice in families, schools, ecclesial communities and other educational contexts.
\end{abstract}

KEYWORDS: Religious-educative process. Pedagogy. Question. Knowledge.

(*) Doutor em Teologia e docente na Escola Superior de Teologia (Faculdades EST), em São Leopoldo/RS, na Área de Concentração de Religião e Educação. Integrante do Grupo de Pesquisa Currículo, Identidade Religiosa e Práxis Educativa. E-mail: remiklein@terra.com.br.

1 Artigo baseado na tese de doutorado: KLEIN, Remí. Histórias em jogo: rememorando e ressignificando o processo educativo-religioso sob um olhar etnocartográfico. São Leopoldo: Escola Superior de Teologia, 2004. 277p. Perguntas existenciais religiosas marcantes foram uma das sete categorias de investigação, a saber: Olhares em perspectivas; Histórias religiosas marcantes; Vivências 


\section{INTRODUÇÃO}

Perguntar é algo natural para uma criança, aliás, para todo ser humano. A pergunta que se coloca como ponto de partida aqui é justamente sobre o lugar e o papel da pergunta no processo educativo e, em especial, no processo educativo-religioso. Ocuparemo-nos, pois, de analisar concepções presentes na pedagogia da pergunta.

\section{POR UMA PEDAGOGIA DA PERGUNTA}

Num texto intitulado Perguntar não ofende. Aproxima, Moacyr Scliar faz referência a Sócrates e à sua inovação na Filosofia pelo seu método de ensino, a maiêutica. Sócrates não afirmava, mas perguntava, por acreditar que pelo diálogo se partejariam as ideias e emergiria uma verdade. Conforme Scliar:

É uma lição mais do que atual, e um princípio que deveria informar a relação entre seres humanos, sobretudo entre pais e filhos. Só que os pais tendem a responder à interrogação com uma exclamação. [...] E a exclamação - um símbolo gráfico que eu, como escritor, eliminaria de qualquer texto - funciona como uma estaca que, cravada na terra de ninguém entre pais e filhos, estabelece o limite que não pode ser ultrapassado.

[...] No caso de pais e filhos há um outro componente, o componente emocional. Uma pergunta é capaz de desencadear uma série de reações nas pessoas, reações que raramente obedecem à racionalidade. $O$ pai, ou a mãe, têm os seus preconceitos. O pai, ou a mãe, têm medo de não saber a resposta certa, têm medo de parecer "ignorantes". Quanto a isso, uma ponderação deve ser feita: "não sei" não é vergonha. "Não sei, meu filho. Vamos descobrir juntos". Querem melhor fórmula para a aproximação entre pais e filhos? (Zero Hora, 25 mar. 2000, Caderno Vida, p. 2).

A pergunta é inerente à nossa vida, à nossa comunicação, aos nossos relacionamentos e ao nosso processo educativo em geral, não só religioso. Já nem mais nos damos conta de que a todo momento perguntamos e isto não se restringe à idade dos porquês, mas abrange a todas as idades, senão vejamos num trecho de $O$ mundo de Sofia como uma jovem de quinze anos também está repleta de perguntas:

Na escola, Sofia tinha dificuldade de se concentrar no que o professor falava. De uma hora para a outra, começou a achar que ele só falava de coisas que não eram

religiosas marcantes; Pessoas de referência religiosa; Símbolos religiosos marcantes; Perguntas existenciais religiosas marcantes; Novos olhares 'em formação'. 
importantes. Por que ele não falava sobre o que é um ser humano, ou então sobre o que é o mundo ou de onde ele tinha surgido?

Ela sentia uma coisa que nunca tinha sentido antes: na escola, e também por toda a parte, as pessoas só se preocupavam com trivialidades. Mas havia questões maiores, mais graves, cujas respostas eram mais importantes do que as matérias normais da escola.

Alguém teria respostas para elas? De qualquer forma, Sofia achava mais importante refletir sobre elas do que quebrar a cabeça decorando verbos irregulares. [...]

Por que será que era tão difícil preocupar-se com estas questões tão importantes e, de certa forma, tão naturais? (GAARDER, 1995, p. 22-23).

Importa, pois, acima de tudo, perguntar e perguntar-se, o que é muito natural para todo ser humano. Em nosso processo educativo, lamentavelmente, porém, a pergunta ficou por demais atrelada ao papel do professor e a uma função de avaliação, cabendo ao aluno dar a resposta certa.

Também no processo educativo-religioso este esquema se reproduziu. Um exemplo típico é a inversão pedagógica que se deu no uso do Catecismo Menor de Martim Lutero no processo de ensino-aprendizagem na fé no decorrer dos últimos cinco séculos nas Igrejas Luteranas. A proposta original do Reformador, ao escrever o Catecismo Menor, em 1529, era de que o pai testemunhasse ao seu filho o conteúdo da sua fé (um mandamento, por exemplo); o filho faria, então, a pergunta: "Que significa isto?”; ao que o pai daria a sua explicação. O que, no entanto, aconteceu é que a maioria das famílias delegou esta tarefa de ensino do Catecismo às comunidades e estas, por sua vez, passaram a exigir por parte das crianças e dos adolescentes um processo de decoreba, ou seja, respostas prontas, enquanto que as perguntas ficaram ao encargo dos adultos como forma de "tomar a lição".

Longe de ser uma pedagogia da pergunta, a prática educativa em geral tornou-se uma pedagogia da resposta, conforme conceitos apresentados por Paulo Freire e Antonio Faundez, em sua obra Por uma pedagogia da pergunta. Os dois autores falam numa "castração da curiosidade" e são unânimes em afirmar que prevalece o ensino que é resposta e não pergunta, e que a pedagogia da resposta é uma pedagogia da adaptação e não da criatividade. A seu ver, importa ensinar e aprender a perguntar e a perguntar-se constantemente, como vemos nas suas falas que valem tanto para educador como para educando:

Creio que [...] a primeira coisa que aquele que ensina deveria aprender é saber perguntar. Saber perguntar-se, saber quais são as perguntas que nos estimulam e estimulam a sociedade. Perguntas essenciais, que partam da cotidianeidade, pois é nela onde estão as perguntas. Se aprendêssemos a nos perguntar sobre nossa própria existência cotidiana, todas as perguntas que exigissem resposta e todo processo pergunta-resposta, que constitui o caminho do conhecimento, começariam por essas perguntas básicas de nossa visa cotidiana [...] 
Creio [...] que o educando inserido num permanente processo de educação, tem de ser um grande perguntador de si mesmo. Quer dizer, não é possível passar de segunda a terça-feira sem se perguntar constantemente. (FREIRE, FAUNDEZ, 1985, p. 48 e 51$)$.

No entender de Freire, todo conhecimento começa pela pergunta e pela curiosidade, que é uma pergunta: "Sem a curiosidade que nos torna seres em permanente disponibilidade à indagação, seres da pergunta - bem feita ou mal fundada, não importa - não haveria a atividade gnosiológica, expressão da possibilidade de conhecer." (1995, p. 76). Numa obra posterior, usa o termo "curiosidade epistemológica" (FREIRE, 1996, p. 27), lançando o seguinte desafio à docência:

Como professor devo saber que sem a curiosidade que me move, que me inquieta, que me insere na busca, não aprendo nem ensino. Exercer a minha curiosidade de forma correta é um direito que tenho como gente e a que corresponde o dever de lutar por ele, o direito à curiosidade. [...]

Estimular a pergunta, a reflexão crítica sobre a própria pergunta, o que se pretende com esta ou com aquela pergunta em lugar da passividade em face das explicações discursivas do professor, espécies de respostas a perguntas que não foram feitas. [...]

O que importa é que professor e alunos se assumam epistemologicamente curiosos. (FREIRE, 1996, p. 95-96).

Conforme Therezinha Motta Lima da Cruz, a resposta fecha caminhos enquanto que a pergunta os deixa abertos e mais emocionantes. Neste sentido, a autora aponta a aventura de perguntar como um desafio para o processo educativo-religioso:

O Ensino Religioso tem (ou pode ter) um conteúdo instigante. A metodologia usada pode acentuar ou abafar essa característica. Acontece que nossas crianças e nossos jovens estão de horizontes encurtados e então a curiosidade encolhe junto. Nossa primeira tarefa, portanto, seria despertar o "perguntador" que todo ser humano já foi [...]. Examinando metodologia e conteúdos do Ensino Religioso, vamos tentar perceber como se encaixa aí a aventura de perguntar. (2003, p. 1).

\section{A PERGUNTA SOB UM NOVO OLHAR}

Com base nessa discussão, coloca-se o desafio de repensarmos o lugar e o papel da pergunta no processo educativo-religioso. Neste sentido, os Parâmetros Curriculares Nacionais do Ensino Religioso iniciam a abordagem sobre a produção do conhecimento religioso da seguinte forma: 
Todo ser humano faz pergunta. Ele interroga a si mesmo e ao mundo. Ao interrogar-se, procura saber quem ele é, para onde vai e de onde veio. Quando a pergunta recai sobre o mundo, o ser humano procura compreender o seu mistério, sua origem e finalidade. $\mathrm{Na}$ experiência do cotidiano existencial, a pergunta rompe com o mesmo. Provoca novas situações. Faz emergir o desconhecido. O manifesto, enquanto manifesto, já é conhecido e por isso não é mais provocador. $\mathrm{O}$ objeto manifesto, porém, guarda sempre outra face como desconhecida, mas sugerida. É um oculto vislumbrado no horizonte. A esse desconhecido que está além-horizonte denominamos de mistério. (FONAPER, 2009, p. 22).

Assim, o mais importante no processo educativo-religioso não são as respostas e as certezas, mas as buscas e os questionamentos. As perguntas existenciais são o ponto de partida e também o ponto de chegada na construção do conhecimento:

$\mathrm{O}$ conhecimento resulta das respostas oferecidas às perguntas que o ser humano faz a si mesmo e ao informante. Às vezes, para fugir à insegurança, resgatando sua liberdade, ele prefere respostas prontas, que apaziguam a sua ansiedade. A raiz do fenômeno religioso encontra-se no limiar dessa liberdade e dessa insegurança. O homem finito, inconcluso, busca fora de si o desconhecido, o mistério: transcende. (FONAPER, 2009, p. 41).

Trata-se de uma concepção não só epistemológica, pedagógica e metodológica, mas também profundamente teológica, no sentido de que certamente estamos mais perto da Transcendência quando fazemos perguntas do que quando pensamos que temos todas as respostas.

Neste sentido, coloca-se o desafio de repensarmos o lugar e o papel da pergunta no processo educativo e, em especial, no processo educativo-religioso e, para tanto, apresentamos um confronto com a pedagogia de Jesus e com a Filosofia com crianças. Para exemplificar o lugar da pergunta na pedagogia de Jesus, transcrevemos um trecho do seu diálogo com um intérprete da lei, que encontramos no evangelho de Lucas:

E eis que certo homem, intérprete da lei, se levantou com o intuito de pôr Jesus em provas, e disse-lhe: Mestre, que farei para herdar a vida eterna?

Então Jesus lhe perguntou: Que está escrito na lei? Como interpretas?

A isto ele respondeu:

Amarás o Senhor teu Deus de todo o teu coração, de toda a tua alma, de todas as tuas forças e de todo o teu entendimento; e amarás o teu próximo como a ti mesmo.

Então Jesus lhe disse: Respondeste corretamente; faze isto, e viverás.

Ele, porém, querendo justificar-se, perguntou a Jesus: Quem é o meu próximo? 
Jesus prosseguiu, dizendo: Certo homem descia de Jerusalém para Jericó, e veio a cair em mãos de salteadores [...].

Qual destes três te parece ter sido o próximo do homem que caiu nas mãos dos salteadores?

Respondeu-lhe o intérprete da lei: O que usou de misericórdia para com ele. Então lhe disse: Vai, e procede tu de igual modo. (Lucas 10.25-37, conforme BÍBLIA SAGRADA, 1969).

A uma pergunta feita pelo intérprete da lei, Jesus retribui-lhe não com uma resposta pronta, mas com duas perguntas, as quais o intérprete da lei mesmo responde. Não se dando, porém, por satisfeito, o intérprete continua perguntando, ao que então Jesus lhe passa a contar uma história. Concluída a parábola, Jesus lança-lhe outra pergunta, ao que o intérprete da lei responde, tirando a sua própria conclusão.

Parece que não sabia falar de outra forma. A cada pergunta teológica de catecismo ele respondia com uma parábola, novela relâmpago com desfecho inesperado. E não há dúvidas de que esta sua mania de contar histórias tenha muito a ver com sua morte. Porque as estórias têm o poder mágico de mexer fundo dentro da alma, atingindo os lugares onde os risos, as lágrimas e as fúrias se aninham... (ALVES, 1982, p. 134).

Estas palavras de Rubem Alves referentes à pedagogia e à teologia de Jesus, evidenciam o quanto a sua vida e os seus ensinamentos estavam interligados e permeados pelas perguntas e qual foi o papel exercido pelas histórias (no seu caso, as parábolas) na abordagem destas questões existenciais no seu ministério. A pedagogia de Jesus caracteriza-se por excelência como uma pedagogia da pergunta.

A pergunta também ocupa um lugar e um papel central na Filosofia, desde o seu surgimento, através do método socrático da maiêutica, já anteriormente referido. Por isso, perguntar e perguntar-se é uma atitude priorizada na proposta de Filosofia para crianças, criada por Matthew Lipman, nos Estados Unidos, a partir dos anos setenta do século passado, e entrementes também bastante difundida em escolas brasileiras, sob o enfoque de Filosofia para e/ou com crianças. De maneira geral, a proposta é desenvolvida a partir de histórias (novelas filosóficas), seguidas de planos de discussão, onde as perguntas ocupam um lugar central no diálogo. (KOHAN, WUENSCH, 1999, v. 1).

\section{A PERGUNTA No ENSINO RELIGIOSO}


A pedagogia da pergunta pode ser vivenciada nas aulas de Ensino Religioso usando a proposta do plano de discussão, com perguntas formuladas não pelo docente, mas pelos discentes, a partir de uma história lida ou narrada. Exemplificamos esta proposta com a abordagem do tema da morte a partir da história Menina Nina: duas razões para não chorar, da autoria de Ziraldo (2002). Após a leitura da história, podemos solicitar que cada estudante formule uma ou mais perguntas sobre ou a partir da história. Anotamos as perguntas no quadro e colocamos entre parênteses a sua autoria. (Não só a resposta, mas também a pergunta tem autoria!) A seguir, agrupamos e reformulamos as perguntas e desenvolvemos o plano de discussão. A título de exemplificação, algumas perguntas formuladas por crianças sobre e a partir da referida história vivenciada numa turma de $4^{\circ}$ ano:

- Onde estavam as outras pessoas da família da Nina? (J)

- Ela dormiu ou morreu? (C)

- E aí, para onde vovó foi? Ela dormiu para sempre ou acordou em outro lugar? (M)

- Por que vovó Vivi nunca falou para a sua neta Nina que ela poderia morrer? (A)

- Será que vou ver minha avó novamente? (E)

Nesse exercício podemos ver o quanto a abordagem de um tema se torna mais existencial quando os educandos participam com suas perguntas suscitadas, sobretudo, a partir de acontecimentos vivenciados na sua infância, relacionados principalmente à perda de familiares e amigos e às perguntas daí decorrentes em relação à morte, evidenciado as dificuldades encontradas para entendê-las e superá-las. Tanto nas perguntas formuladas sobre e a partir da história, como no diálogo desencadeado a partir daí, percebemos que muito rapidamente as crianças não estão mais falando sobre a morte da vovó Vivi e os sentimentos da menina Nina, mas passam a falar de si e de suas histórias de vida.

Vemos que as pessoas, especialmente na sua infância, a partir de suas experiências de vida e de perdas de familiares e amigos, fazem inúmeras perguntas sobre Deus, céu, doença, sofrimento, morte e outras questões existenciais. Muitas vezes, o primeiro contato que as crianças têm com a morte é por ocasião da morte de um animal, um animal de estimação talvez, e esta experiência pode ajudá-las a entenderem a morte de um parente ou amigo, quando ocorrer.

A maioria das crianças está disposta e até ansiosa para falar sobre este assunto, ao contrário de muitas pessoas adultas que, muitas vezes, o consideram 
tabu. As crianças representam a morte, fazem perguntas a seu respeito e também expressam seu medo diante dela. Há crianças, no entanto, temerosas demais para fazerem perguntas e que precisam ser encorajadas para não reprimirem seus medos e questionamentos sobre esta questão.

Outro escritor marcante neste sentido é Rubem Alves, por abordar e desmistificar temas dolorosos com seus leitores de todas as idades por meio de "estórias". Em Estórias para pequenos e grandes, ele dirige a seguinte palavra inicial "aos contadores das estórias", falando sobre as suas motivações na escolha dos referidos temas e sobre a importância da presença de alguém ao lado da criança durante a narração destas "estórias dolorosas":

[...] Escrevi estas estórias em torno de temas dolorosos, que me foram dados por crianças. Não é possível fazer de conta que eles não existem. [...] O objetivo da estória é dizer o nome, dar às crianças símbolos que lhes permitam falar sobre seus medos. E é sempre mais fácil falar sobre si mesmo fazendo de conta que se está falando sobre flores, sapos, elefantes, patos...

Há estórias que podem ser escutadas em disquinhos ou simplesmente lidas, sozinhas... São as estórias engraçadas. Outras devem ser contadas por alguém.

Quando se anda pelo escuro do medo, é sempre importante saber que há alguém amigo por perto. Alguém está contando a estória. Não estou sozinho... Nem o livro que se lê e nem o disquinho que se ouve têm o poder de espantar o medo.

É preciso que se ouça a voz de um outro e que diz:

- Estou aqui, meu filho... (1994, p. 7-8).

É fundamental a adequação da linguagem nas histórias contadas às crianças e no diálogo com elas sobre suas perguntas existenciais, considerando as suas dificuldades de compreensão e evitando, na medida do possível, velhos clichês. Nem sempre é bom dizer que 'Deus levou a avó', porque então as crianças podem ver em Deus um tipo de sequestrador que pega as pessoas à força. Da mesma forma, se dissermos 'A avó foi para junto de Jesus', isto pode sugerir que a avó não gostava de nós e preferiu ficar com Jesus.

As crianças esperam por respostas às suas perguntas e querem ouvi-las imediatamente. Claro que não temos condições de saber respostas a todas as perguntas que as crianças fazem, mas temos de cuidar para não contar mentiras ou meias verdades para nos safar de uma pergunta difícil de responder. Para muitas perguntas não há uma resposta-padrão. Na hora de responder, temos de levar em consideração a idade da criança, sua capacidade de compreensão e sua experiência de vida. 
Em geral, as crianças esperam uma resposta direta, objetiva e simples às suas perguntas, o que não significa que a resposta deva ser simplória. É importante responder apenas aquilo que a criança perguntou e não sobrecarregá-la com informações. Ao mesmo tempo, não devemos subestimar seus níveis de compreensão. Facilita se conseguimos tornar a resposta condizente com a sua experiência de vida. Temos de escutar não só com os ouvidos, mas também com o coração, pois, às vezes, o que passa pela cabeça das crianças não é exatamente a pergunta que nos estão fazendo naquele instante.

Concordamos com Jeremie Hughes, ao afirmar: “A nossa habilidade em responder às perguntas das crianças depende, em alto grau, das respostas que encontramos para nós mesmos para as grandes e pequenas questões existenciais.” (1994, p. 14). Este é, pois, um desafio a ser enfrentado em nossa formação pessoal e profissional como educadores. Neste sentido, também, é importante entendermos e levarmos as crianças a entenderem, aos poucos, que pode haver pontos de vista diferentes do nosso em determinadas questões, que há perguntas que admitem respostas alternativas e que há perguntas para as quais não temos respostas. Nossas perguntas existenciais nunca cessam, mas elas são o ponto de partida e de chegada no processo educativo-religioso ou, conforme Eli Benincá, elas são "fonte de transcendência”:

Sempre quando alguém não tem o domínio sobre determinada situação ou objeto ele pergunta para receber uma informação e, com isso, cessa a curiosidade que gerou a pergunta. Mas existem outras perguntas cujas respostas nunca satisfazem nossa curiosidade, principalmente quando se referem à vida, ao futuro, às forças superiores e aos mistérios do além. As perguntas estão presentes já na infância do ser humano e repetem-se por toda a vida. Nunca cessam. Há um espaço inacessível ao ser humano enquanto ser histórico e finito. A curiosidade que nos leva ao inacessível é também fonte de transcendência. (2001, p. 62).

$\mathrm{Na}$ pergunta do ser humano podemos reconhecer a sua busca pela transcendência e, a partir daí, somos desafiados a trabalhar o Ensino Religioso numa relação com as histórias e as perguntas existenciais dos educandos. Assim, para a escola e para nós docentes do Ensino Religioso e da educação em geral coloca-se o seguinte desafio, conforme os Parâmetros Curriculares Nacionais do Ensino Religioso:

[...] o processo de aprendizagem se fundamenta na busca do saber e no desejo de transcendência. Toda a pergunta, nesta perspectiva, se torna legítima. A Escola não pode negar conhecimento, respostas, às perguntas feitas pelos educandos. Todas as perguntas, não importando de que campo sejam, exigem a atenção da Escola. 
Diante do mistério do Transcendente, a perplexidade do educador necessita antecipar-se à do educando para que juntos possam responder às questões trazidas ou estimular outras perguntas. [...]

Desse profissional espera-se que esteja disponível para o diálogo e seja capaz de articulá-lo a partir de questões suscitadas no processo de aprendizagem do educando. (FONAPER, 2009, p. 42-43).

\section{CONSIDERAÇÕES FINAIS}

Com base em reflexões a partir de referenciais da maiêutica de Sócrates, da pedagogia de Jesus, dos catecismos de Lutero, da filosofia para crianças de Lipman, da proposta pedagógica de Freire e dos Parâmetros Curriculares Nacionais de Ensino Religioso do FONAPER, buscamos, pois, fundamentar uma pedagogia da pergunta a ser repensada, redescoberta e ressignificada na práxis educativo-religiosa em famílias, escolas, comunidades eclesiais e outros contextos educacionais.

A pergunta e o ato de perguntar estão na base dos nossos relacionamentos e de nossos conhecimentos. Assim, entendemos que este possa e deva ser também o ponto de partida e de chegada no Ensino Religioso em nossas escolas, com vistas a uma abordagem mais antropológica e mais existencial.

\section{REFERÊNCIAS}

ALVES, Rubem. A alegria de ensinar. 2. ed. São Paulo: Ars Poética,1994.

. Variações sobre a vida e a morte: a teologia e a sua fala. São Paulo:

Paulinas, 1982.

BENINCÁ, Eli. O Ensino Religioso e a fenomenologia religiosa. In: KLEIN, Remí; WACHS, Manfredo Carlos; FUCHS, Henri Luiz (Org.). O Ensino Religioso e o Pastorado Escolar: novas perspectivas - princípios includentes. São Leopoldo, RS: IEPG, 2001. p. 54-73.

BÍBLIA SAGRADA. Antigo e Novo Testamento. Tradução em português por João Ferreira de Almeida. Ed. rev. e atualizada no Brasil. Brasília, DF: Sociedade Bíblica do Brasil, 1969.

CRUZ, Therezinha Motta Lima da. Vivências metodológicas do Ensino Religioso: a aventura de fazer perguntas. 2003. Trabalho apresentado ao III Fórum Estadual de Ensino Religioso, Porto Alegre, 2003.

FONAPER - Fórum Nacional Permanente do Ensino Religioso. Parâmetros

Curriculares Nacionais: Ensino Religioso. 9. ed. São Paulo: Mundo Mirim, 2009.

FREIRE, Paulo. À sombra desta mangueira. São Paulo: Olho D’Água, 1995. 
FREIRE, Paulo; FAUNDEZ, Antonio. Por uma pedagogia da pergunta. Rio de Janeiro: Paz e Terra, 1985.

GAARDER, Jostein. O mundo de Sofia: romance da história da filosofia. São Paulo: Companhia das Letras, 1995.

HUGHES, Jeremie. Por que o céu não cai? E outras perguntas das crianças. São Leopoldo, RS: Ed. Sinodal, 1994.

KLEIN, Remí. Histórias em jogo: rememorando e ressignificando o processo educativo-religioso sob um olhar etnocartográfico. São Leopoldo: Escola Superior de Teologia, 2004. 277p.

KOHAN, Walter Omar; WUENSCH, Ana Míriam (Org.). Filosofia para crianças: a tentativa pioneira de Matthew Lipman. 2. ed. Petrópolis, RJ: Vozes, 1999. v. 1.

SCLIAR, Moacyr. Perguntar não ofende. Aproxima. Zero Hora, Porto Alegre, 25 mar. 2000. Caderno Vida, p. 2.

ZIRALDO. Menina Nina: duas razões para não chorar. 4. ed. São Paulo: Melhoramentos, 2002. 